\title{
Projections of healthy working life expectancy in England to the year 2035
}

\author{
Marty Lynch $\oplus^{1,2} \bowtie$, Milica Bucknall', Carol Jagger $\circledast^{3}$ and Ross Wilkie ${ }^{1,2}$
}

\begin{abstract}
UK state pension age is rising in response to life expectancy gains but population health and job opportunities may not be sufficient to achieve extended working lives ${ }^{1-3}$. This study aimed to estimate future trends in healthy working life expectancy (HWLE) from age 50 to 75 for men and women in England. Using the 'intercensal' health expectancy approach, annual period HWLE from 1996 to 2014 was estimated using cross-sectional Health Survey for England data and mortality statistics ${ }^{4-7}$. HWLE projections until the year 2035 were estimated from Lee-Carter forecasts of transition rates $^{8}$. Projections of life expectancy from age 50 showed gains averaging 10.7 weeks (0.21 years) and 6.4 weeks ( 0.12 years) per calendar year between 2015 and 2035 for men and women respectively. HWLE has been extending in England but gains are projected to slow to an average of 1 week per year for men (0.02 years) and 2.8 weeks (0.05 years) per year for women between 2015 and 2035. Modest projected HWLE gains and the widening gap between HWLE and life expectancy from age $\mathbf{5 0}$ suggest that working lives are not extending in line with policy goals. Further research should identify factors that increase healthy working life.
\end{abstract}

Population aging and further expected increases in life expectancy have led many countries to seek to extend working lives by increasing state pension age ${ }^{1,9}$. For example, France, Germany and Spain will increase the state pension age to 67 years between 2023 and 2029 and the UK state pension age will increase to 67 by the end of 2028 with further increases to 68 expected to be brought forward to 2037-2039 (refs. ${ }^{1,9}$ ). Achieving policy objectives to extend later working lives requires a sufficient proportion of people in the population to be able to work for longer, along with appropriate job opportunities. Poor physical and mental health as well as employment levels, job opportunities and the workplace environment are key reasons for early departure from the workforce-particularly in adults aged 50 and over $^{2,10-12}$. Socio-demographic factors are also linked to health and work outcomes; deprivation and lower educational attainment are associated with more health problems and lower levels of work ${ }^{3,10,13,14}$. Sex and gender are associated with social, economic and biological determinants and consequences of health and illness ${ }^{15,16}$.

The links between health and work highlight the need to maintain a healthy workforce if policy changes to extend working lives are to be realized. Healthy Working Life Expectancy (HWLE), which is the average number of years from age 50 that people can expect to be healthy and in work, is lower than ten years in England ${ }^{3,17,18}$. Life expectancy gains may not translate to increasing HWLE ${ }^{3,17,18}$ since there is no consistent correlation between mortality rates and populations' burdens of poor health ${ }^{19}$. Social inequalities in disability free life expectancy are growing in the UK and average gains in healthy life years are lagging behind the rest of Europe ${ }^{20,21}$.
How HWLE might change in the coming years, as state pension age continues to rise, is unknown. If state pension age rises but HWLE gains do not keep pace, individuals (especially those with chronic health problems) may increasingly face challenges securing suitable employment or engaging productively and healthily at work, to the detriment of their health and well-being and that of their families ${ }^{22-26}$.

The aim of this study was to investigate past and expected future HWLE trends for men and women in England by projecting HWLE to the year 2035. Achieving this depended on the availability of health and work survey data for adults aged 50 years and older, and the feasibility of applying projection and health expectancy methods. The approach presented in this paper applies standard demographic forecasting methods to project HWLE using annual cross-sectional data on the age-specific prevalence of being healthy and working from the Health Survey for England (HSE).

\section{Results}

Forecasts of HWLE (from age 50 to end of life) and life expectancy were based on mortality rates from 1996 to 2018 from national mortality statistics and rates of health (absence of long-standing limiting illness) and work participation from 1996 to 2014 estimated from HSE data. Because of low rates of health and work participation in the HSE data beyond age 75 during the study period, feasibility of the analyses required the assumption that rates of both health and work participation in adults aged over 75 was negligible. Although HSE data are not available by individual year of age after 2014, data up to 2018 could be included in a sensitivity analysis using the Sullivan method.

Life expectancy projections. Life expectancy from age 50 for men was 26.20 years in 1996, 30.60 years in 2015 (the first year of HWLE projections) and 31.60 years from age 50 in 2018 (the most recent year with observed mortality data) (Table 1 and Supplementary Table 1). Life expectancy from age 50 for men was projected as 31.97 years $(95 \%$ confidence interval $(\mathrm{CI})=31.71-32.22)$ in 2020 and 34.70 years $(95 \% \mathrm{CI}=33.75-35.56)$ in 2035. Projected life expectancy for men in 2035 was 1.20 years higher than the Office for National Statistics (ONS) 2018-based estimate of 33.5 years from age 50 .

Life expectancy from age 50 for women was 30.39 years in 1996, 33.65 years in 2015 and 34.51 years in 2018 (Table 2 and Supplementary Table 2). Life expectancy from age 50 for women was projected as 34.79 years $(95 \% \mathrm{CI}=34.51-35.08)$ in 2020 and 36.72 years $(95 \% \mathrm{CI}=35.69-37.70)$ in 2035 . The projected life expectancy point estimate for women in 2035 was 0.72 years higher than the ONS 2018-based estimate of 36.0 years from age 50. 
Table 1 | HWLE and life expectancy estimates from age 50 for men: projections of HWLE for the years 2015, 2020, 2025, 2030 and 2035 , life expectancy observed (2015) and projected (2020, 2025, 2030, 2035), Sullivan method HWLE estimate for the year 2015 and official published life expectancy estimate for the year 2015 and projections for the years 2020, 2025, 2030 and 2035

\begin{tabular}{|c|c|c|c|c|c|c|c|c|}
\hline \multirow{2}{*}{$\begin{array}{l}\text { Men } \\
\text { Year }\end{array}$} & \multicolumn{3}{|c|}{ Intercensal method + Lee-Carter projections } & \multirow{2}{*}{$\begin{array}{l}\text { Sullivan method } \\
\text { HWLE }(95 \% \mathrm{Cl})\end{array}$} & \multicolumn{4}{|c|}{ ONS past and 2018-based life expectancy projections } \\
\hline & $\begin{array}{l}\text { Projected HWLE } \\
(95 \% \mathrm{Cl})\end{array}$ & $\begin{array}{l}\text { Observed life } \\
\text { expectancy }\end{array}$ & $\begin{array}{l}\text { Projected life } \\
\text { expectancy }\end{array}$ & & $\begin{array}{l}\text { Past life } \\
\text { expectancy }\end{array}$ & $\begin{array}{l}\text { Projected life } \\
\text { expectancy }\end{array}$ & Low variant & High variant \\
\hline 2015 & $\begin{array}{l}8.67 \\
(6.57-10.73)\end{array}$ & 31.33 & & $9.82(9.31-10.33)$ & 31.4 & & & \\
\hline 2020 & $\begin{array}{l}8.85 \\
(4.98-12.03)\end{array}$ & & $\begin{array}{l}31.97 \\
(31.71-32.22)\end{array}$ & & & 32.0 & 31.8 & 32.2 \\
\hline 2030 & $\begin{array}{l}8.99 \\
(2.90-12.96)\end{array}$ & & $\begin{array}{l}33.83 \\
(33.01-34.59)\end{array}$ & & & 33.0 & 32.6 & 33.4 \\
\hline 2035 & $9.05(2.16-13.28)$ & & $\begin{array}{l}34.70 \\
(33.75-35.56)\end{array}$ & & & 33.5 & 32.7 & 34.1 \\
\hline
\end{tabular}

State 1: healthy and in work; state 2: not healthy and/or not in work (including: healthy and not in work, not healthy and in work, not healthy and not in work); state 3: dead. Data for the estimation of HWLE from 1996 to 2014 (1996-2017 for the Sullivan method estimates) were examined; data for the estimation of life expectancy from 1996 to 2018 were examined. The ONS low and high variants reflect less optimistic and more optimistic future demographic scenarios, respectively based on trend calculations and expert opinions. See Supplementary Table 1 for results for the years $1996-2035$.

Table 2 | HWLE and life expectancy estimates from age 50 for women: projections of HWLE for the years 2015, 2020, 2025, 2030 and 2035, life expectancy observed (2015) and projected (2020, 2025, 2030, 2035), Sullivan method HWLE estimate for the year 2015 and the official published life expectancy estimate for the year 2015 and projections for the years 2020, 2025, 2030 and 2035

\begin{tabular}{|c|c|c|c|c|c|c|c|c|}
\hline \multirow{2}{*}{$\begin{array}{l}\text { Women } \\
\text { Year }\end{array}$} & \multicolumn{3}{|c|}{ Intercensal method + Lee-Carter projections } & \multirow{2}{*}{$\begin{array}{l}\text { Sullivan method } \\
\text { HWLE }(95 \% \mathrm{CI})\end{array}$} & \multicolumn{4}{|c|}{ ONS past and 2018-based life expectancy projections } \\
\hline & $\begin{array}{l}\text { Projected HWLE } \\
(95 \% \mathrm{Cl})\end{array}$ & $\begin{array}{l}\text { Observed life } \\
\text { expectancy }\end{array}$ & $\begin{array}{l}\text { Projected life } \\
\text { expectancy }\end{array}$ & & $\begin{array}{l}\text { Past life } \\
\text { expectancy }\end{array}$ & $\begin{array}{l}\text { Projected life } \\
\text { expectancy }\end{array}$ & Low variant & High variant \\
\hline 2015 & $7.49(5.61-9.62)$ & 34.26 & & $8.10(7.64-8.55)$ & 34.3 & & & \\
\hline 2020 & $\begin{array}{l}7.74 \\
(4.50-11.53)\end{array}$ & & $\begin{array}{l}34.79 \\
(34.51-35.08)\end{array}$ & & & 34.8 & 34.7 & 35.0 \\
\hline 2025 & $\begin{array}{l}8.02 \\
(3.98-12.52)\end{array}$ & & $\begin{array}{l}35.46 \\
(34.79-36.12)\end{array}$ & & & 35.2 & 35.0 & 35.5 \\
\hline 2035 & $8.57(3.28-13.87)$ & & $\begin{array}{l}36.72 \\
(35.69-37.70)\end{array}$ & & & 36.0 & 35.4 & 36.6 \\
\hline
\end{tabular}

State 1: healthy and in work (HWLE); state 2: not healthy and/or not in work (including: healthy and not in work, not healthy and in work, not healthy and not in work); state 3: dead. Data for the estimation of HWLE from 1996 to 2014 (1996 to 2017 for the Sullivan method estimates) were examined; data for the estimation of life expectancy from 1996 to 2018 were examined. The ONS low and high variants reflect less optimistic and more optimistic future demographic scenarios, respectively based on trend calculations and expert opinions. See Supplementary Table 2 for the results for the years $1996-2035$.

HWLE projections. For men, HWLE from age 50 during the observed years was calculated to increase from 6.93 in 1996 to 8.94 in 2014 (the most recent year with observed age-specific health and work for the HWLE calculation) (Supplementary Table 1). Projected HWLE from age 50 for men was 8.67 years $(95 \%$ $\mathrm{CI}=6.57-10.73)$ in 2015 , increasing to 8.85 years $(95 \% \mathrm{CI}=4.98-$ $12.03)$ in 2020 and 9.05 years $(95 \% \mathrm{CI}=2.16-13.28)$ in 2035 (Table 1 and Supplementary Table 1).

For women, HWLE from age 50 during the observed years increased from 4.94 in 1996 to 6.85 in 2014 (Supplementary Table 2). Projected HWLE from age 50 for women was 7.49 years $(95 \%$ $\mathrm{CI}=5.61-9.62)$ in 2015 increasing to 7.74 years $(95 \% \mathrm{CI}=4.50$ $11.53)$ in 2020 and 8.57 years $(95 \% \mathrm{CI}=3.28-13.87)$ in 2035 (Table 2 and Supplementary Table 2).

Expected future trends in the relationship between HWLE and life expectancy. Average HWLE gains are not expected to keep pace with average life expectancy gains, meaning a likely decrease over time in the percentage of life expectancy from age 50 spent healthy and in work. Life expectancy from age 50 for men in 2035 was projected to be 4.10 years higher than that observed in 2015 (the first year for which HWLE was projected), implying an average annual gain of 10.7 weeks ( 0.21 years) per year. Life expectancy from age 50 for women in 2035 was projected to be 2.46 years higher than that observed in 2015 - an average gain of 6.4 weeks per year $(0.12$ years). Throughout 1996 to 2014, the average estimated gain per year in HWLE from age 50 was 5.8 weeks for men ( 0.11 years) and 5.5 weeks for women (0.11 years) (Figs. 1 and 2). From 2015 to 2035, HWLE gains were projected to slow to an average of 1 week per year for men ( 0.02 years) and 2.8 weeks per year for women ( 0.05 years).

Sensitivity analyses results. HWLE point estimates calculated using the Sullivan method were almost 1 year higher for men and 0.78 years higher for women from 1996 to 2014 than the primary estimates calculated using the intercensal method (Table 3). HWLE trends over time were visually similar using both methods (Figs. 1 and 2). From 1996 to 2014, Sullivan method HWLE estimates increased by an average of 6.4 weeks per year for men ( 0.12 years) 


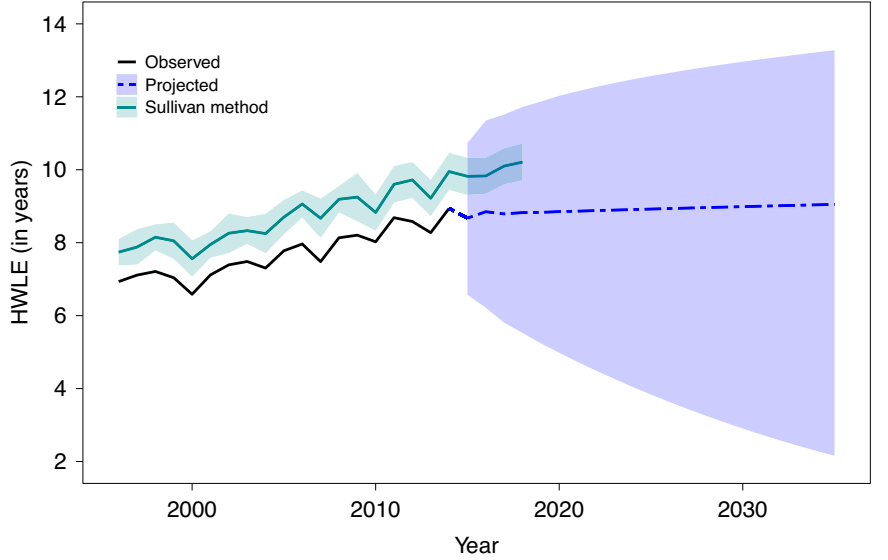

Fig. 1 | Projections of HWLE from age 50 for men. Observed (1996-2014, black line) and projected HWLE (2015-2035, blue dashed line with 95\% $\mathrm{Cls}$ ) estimates for men shown with Sullivan method estimates (green line with $95 \% \mathrm{Cls}$ ). $\mathrm{Cls}$ are derived from uncertainty forecasts for changes over time in mortality and transition rates and in prevalence of being healthy and in work at age 50 .

and 6.3 years for women ( 0.12 years) compared to average yearly gains of 5.8 weeks ( 0.11 years) and 5.5 weeks ( 0.11 years), respectively in the intercensal HWLE estimates. Although HWLE projections are expected smoothed trends without fluctuation typical of point estimates from observed years, the Sullivan method HWLE estimates from 2015 to 2018 maintained a similar relationship to the projected HWLE. HWLE increases observed for men and women from 2015 to 2018 using the Sullivan method appear to be slowing, which is consistent with inferences from HWLE projections.

There were no substantial differences in HWLE estimates or $95 \%$ CIs for men or women either assuming mortality rates to be the same from both alive states $(R=1)$ or assuming mortality rates to be twice as high from the unhealthy and/or not working state $(R=2)$ (Supplementary Tables 1-4 and supplementary Note).

\section{Discussion}

The length of healthy working life from age 50 has been extending for both men and women in England but gains appear to be stalling. Between 2015 and 2035, expected HWLE gains are also lower than the life expectancy gains of 3.37 years for men and 2.46 years for women expected from age 50. HWLE is expected to be 1.08 years longer for women and 0.38 years for men in 2035 compared to 2015. The modest expected increase in HWLE suggests that working lives are not necessarily extending in line with policy goals, which may result in an increase in older adults requiring benefits due to being unhealthy or out of work. Further, raising the state pension age implies an expected extension of full-time work. This HWLE projection analysis included part-time workers; results of a full-time only or full-time equivalent analysis would be lower. Both working life expectancy and HWLE may be more strongly correlated with healthy life expectancy than with life expectancy ${ }^{27}$. Life expectancy improvements widespread across Europe and worldwide have been the basis for raising the state pension age in the UK but smaller improvements in population health at older ages may be a barrier to increasing both employment at older ages and length of healthy working life $\mathrm{e}^{1,28-32}$. While life expectancy at age 65 increased from 2000-2002 to 2012-2014, healthy life expectancy at age 65 stayed the same; gains in life expectancy from age 65 were unhealthy years leading to an increasing proportion of years in later life spent in poor health ${ }^{33}$. While there has been little evidence of compression of morbidity in the UK, a few European countries have experienced

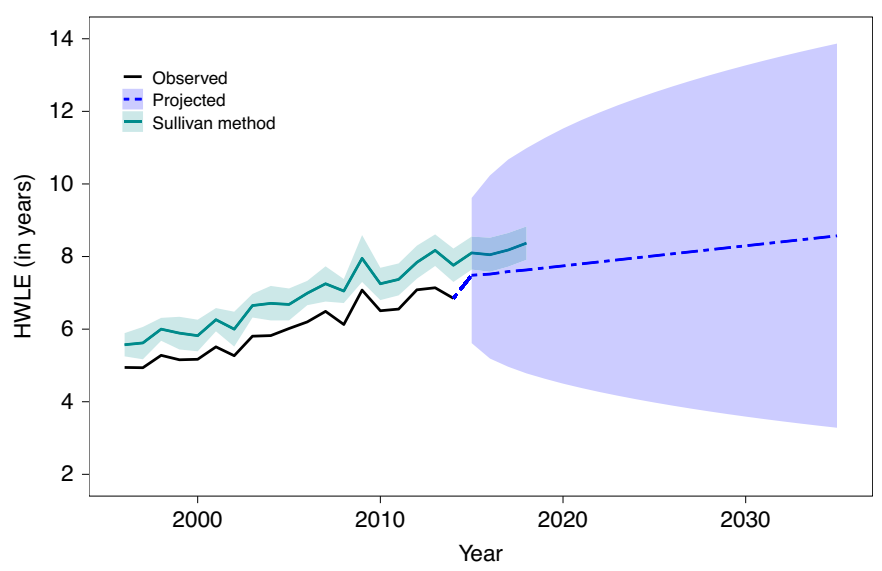

Fig. 2 | Projections of HWLE from age $\mathbf{5 0}$ for women. Observed HWLE (1996-2014, black line) and projected HWLE (2015-2035, blue dashed line with $95 \% \mathrm{Cls}$ ) estimates for women shown with Sullivan method estimates (green line with $95 \% \mathrm{Cls}$ ). Cls are derived from uncertainty forecasts for changes over time in mortality and transition rates and in prevalence of being healthy and in work at age 50 .

absolute or relative compression of morbidity and a greater dynamic equilibrium, where years of unhealthy life are expanding due to increases in milder levels of ill-health ${ }^{21}$ the latter may be of particular interest in terms of HWLE. Moreover, that inequalities are widening and life expectancy and healthy life expectancy at age 65 have remained largely unchanged for men and women in England since 2012-2014 (refs. ${ }^{33,34}$ ) is consistent with the HWLE trends forecasted in this study.

Women's shorter observed and projected HWLE compared to men despite longer life expectancy reflects women's historically lower state pension age and employment rates $^{35}$. This difference also highlights the role of various lifestyle, biological, workplace and social factors in the broader biopsychosocial model that may influence work engagement and length of healthy working life ${ }^{27}$. Increases to state pension age for women, implemented from 2010, are likely to have contributed to increasing employment rates in recent years. Estimates of HWLE trends in England in recent years are consistent with the findings of this study in showing larger increases for women than men $^{36}$. The projected narrowing of the gap between length of healthy working life from age 50 for men and women in England is in keeping with a narrowing of the sex difference in working life expectancy from age 50 across Europe ${ }^{27}$. This forecast - and the small HWLE gains projected - could result from the HSE data reflecting the impact of the financial crisis of 2007-2008 on jobs later in our study period, as well as austerity measures introduced in the UK from 2010, reducing the number of jobs or job quality ${ }^{37-40}$. The Lee-Carter forecasting approach bases projections on an observed age-period pattern in the data and does not attempt to anticipate policy changes or other interventions; therefore, efforts to create good work opportunities for older workers may help to avoid the projected stalling of HWLE in the future.

As well as mortality rates ${ }^{41}$, the coronavirus (COVID-19) pandemic has impacted on both health and employment levels and the impact on HWLE will become clearer as health and employment rates stabilize in the coming years. Education inequalities exacerbated through school closures due to COVID-19 (refs. ${ }^{14,42}$ ) may disadvantage the next generation of workers who will be expected to remain in employment until older ages. Furthermore, job loss is linked to a variety of psychosocial and objective contextual factors (for example, inadequate support at work), which are more likely to affect people in occupations requiring fewer educational qualifications and in areas of higher deprivation ${ }^{43}$. 
The opportunity to combine different data sources was a strength of this study; incorporating the most recent mortality data into the analysis allowed the results to reflect that estimates of life expectancy in England have been revised down in recent years ${ }^{44}$. Life expectancy projections were higher than official projected point estimates by the ONS, which are accompanied by estimates of low and high variants based on expert judgement rather than 95\% CIs from statistical methods. If the life expectancy projections obtained in this study are overestimated, the gap between life expectancy and HWLE gains may be narrower than observed, although the HWLE would also be reduced by increased mortality in the 50-75 age range.

Estimates of HWLE using the intercensal and Sullivan methods were several years lower than HWLE estimates previously published using the interpolated Markov chain approach with data from the English Longitudinal Study of Ageing (10.94 years for men and 8.25 years for women from age 50$)^{3}$. In this study, to forecast HWLE necessitated a simplified multistate modeling approach using the intercensal method (for which data collected annually from adults of all ages in the HSE were best suited), although limitations and biases of this health expectancy estimation approach are not yet well understood. These results suggest that HWLE estimates may be underestimated as a result of sensitivity to the model assumption of net irreversible transitions (instead of allowing return to the healthy and working state) implemented in the intercensal and Sullivan methods, while the robustness of the Sullivan time trends likely extends to trends observed using the intercensal method.

The sensitivity analysis demonstrating the robustness of the HWLE to $R$ is a key strength of this study because the true ratio is difficult to estimate due to the impermanence of people's transitions between health and work statuses.

Operationalizing health using self-reported long-standing limiting illness is a strength. Theoretical models highlight that biological and nonbiological factors drive perceptions of health ${ }^{22}$. The aspect of health driving ability to function (including work) is likely to be more directly linked to whether long-standing limiting illness is present than self-assessed general health, which is interpreted inconsistently between individuals and cultures and is associated with respondents' feelings of vitality ${ }^{45}$. The operationalization of health via self-reported limitation is compatible with the biopsychosocial relationship between health and work; for example, limitations experienced due to illness may be removed through employer adaptations ${ }^{17}$.

Limitations of our study concern the estimation method and HSE sample size. First, the choice of the HWLE estimation method was based on feasibility rather than taking a Markov chain approach $^{3,5}$. No approach to estimate the CIs associated with each point estimate is a limitation of the intercensal approach. (Those calculated for the HWLE projections derive from the projection component.) The intercensal method assumes that the age pattern for the rate of transition from healthy and working to unhealthy and/or not working, as well as the overall population mortality rate, are well approximated by an exponential function. This, and the modeling of net transition rates instead of the two-way transitions in and out of health and work states possible in reality, could help to explain why estimates using both the intercensal approach and Sullivan method differ from previously published interpolated Markov chain results ${ }^{3}$. Second, the calculations of past HWLE and estimation of projected HWLE were limited by low sample sizes in the HSE datasets for health and work prevalence data to the extent that smoothing was essential. The sample sizes also meant that it was necessary to examine period life expectancy and HWLE because sequential cross-sectional measurements of the age-specific prevalence of being healthy and in work were too varied to be feasibly and meaningfully analyzed using a cohort approach. Cohort HWLE estimates using the intercensal approach may be less biased than Sullivan estimates due to avoiding the assumption of stationary mortality rates and population prevalence of being healthy and in work throughout the life course for each year ${ }^{5}$. That HSE survey weights were not available before 2003 may be a limitation affecting representativeness of the earlier study years. The unavailability of age-specific HSE data after 2014 was a further limitation because this meant that the years since then, already passed at the time of this study, were projected, thereby adding additional uncertainty to the projections. Although this study aimed to estimate HWLE and life expectancy from age 50 to end of life, it was necessary to assume negligible rates of health and work participation after age 75 due to very low and zero observed rates of health and work participation. Recent HSE years showed nonzero rates of health and work engagement after age 75; HWLE projections from age 50 to end of life could be slightly underestimated due to likely increasing work engagement in good health at these older ages.

There are several key implications of this study for policymakers and further research. Importantly, the study indicates that policies to extend working lives are likely to fail without additional policies targeting population health, job opportunities, management of health conditions for people in work and workplace environments. However, the Lee-Carter forecasting approach did not take into account the effect on HWLE of other factors that may change; the HWLE projections presented suggest future trends based on relevant factors remaining the same (or continuing the same trends) as observed in the study period. Whether people in England can work for longer may depend on interventions to improve population health and access to suitable employment, particularly since earlier onset of multiple health conditions (multi-morbidity) is expected in future cohorts of older people ${ }^{46}$. More work is needed to examine the links between population health, demographics, workplace and lifestyle factors with HWLE. There are many factors (for example, climate change) that may influence HWLE in the coming years in ways that we cannot currently predict; methodological development is required to account for the trends presently foreseen in lifestyle behaviors (for example, activity and obesity levels) and workplace factors. The new demonstration of HWLE estimation using the intercensal approach compared to more established approaches has important implications for methodological development of the health expectancy estimation tool kit.

Although difficulty in identifying a suitable data source may be a barrier to updating the HWLE projections using these methods in the future, these findings provide a useful insight into the potential trajectory of future HWLE change for men and women in England. Recognizing the possibility that HWLE estimates and projections are likely to have been underestimated in this study, there remains a gap between expected levels of working (until the state pension age on average) and achieved length of healthy working life in men and women in England. There is a need to monitor current and projected HWLE to examine the impact of policy changes in the coming years as state pension age continues to rise and people are expected to work for longer. The projected slowing of HWLE gains compared to life expectancy indicates a need to better understand the factors that drive, or are barriers to, extending healthy working life as well as how HWLE varies between subpopulations affected by key age-associated health conditions. Initiatives to improve population health and well-being, reduce inequalities and improve access to suitable job opportunities may be essential to continue the upward trajectory of HWLE for men and women as state pension age rises.

\section{Methods}

Ethical approval for the HSE is reviewed yearly and was obtained from the East Midlands Nottingham 2 Research Ethics Committee (ref. no. 15/EM/0254) for the 2018 survey.

Study design and participants. Total life expectancy from age 50 and HWLE from age 50 to end of life were estimated and forecasted using age-specific rates of mortality and health and work participation. Age-specific mortality rates from age 
50 to 100 for men and women separately were identified from the UK ONS single year life tables from 1996 (to correspond to the start of the HSE data used) to 2018 (the most recent year available at the time of the analysis) ${ }^{4}$

Data on health and work participation were used from the HSE. Full details of the HSE study design, methods and response rates have been published previously $y^{6,47}$. Briefly, the series of annual HSE surveys started in 1991 using household questionnaires, personal interviews and self-completion questionnaires to collect data from representative samples of England's community-dwelling general population (using survey weighting from 2003). HSE data were obtained from the UK Data Service (freely available to registered researchers from https://doi.org/10.5255/UKDA-SN-7919-3) and used to identify the prevalence (with weights for the years 2003-2014) of being healthy and in paid work at each year of age from age 50 upwards from 1996 to 2014 using the following variables: limiting long-standing illness (to identify health status; included in the HSE from 1996); work participation status; and year of age. More recent HSE data (2015 onwards) could not be used because it provided only grouped age variables. For feasibility, a data-driven assumption was made that the age-specific rates of being both healthy and in work were negligible after age 75. HSE sample sizes each year from 1996 to 2014 for the ages 50-75 ranged from 1,785 (2009) to 5,798 (2008) after excluding respondents with missing health and/or work data (Supplementary Table 5). For each year from 1996 to 2014 for respondents aged 50-75, the number of respondents with missing health and/or work data ranged from 0 (1996) to 10 (2014).

Assessment of health and work states. HWLE is defined as the average number of years people in a population are expected to be both healthy and in work from age $50\left(\right.$ refs. $\left.{ }^{3,18}\right)$. Health and work statuses were self-reported in the HSE surveys from 1996.

Health was captured through two survey items on limiting long-standing illness (revised in 2012): 'Do you have any long-standing illness, disability or infirmity? By long-standing I mean anything that has troubled you over a period of time or that is likely to affect you over a period of time?' and if so, 'Does this illness or disability (do any of these illnesses or disabilities) limit your activities in any way?' (HSE 1996-2011); 'Do you have any physical or mental health conditions or illnesses lasting or expected to last 12 months or more?' and if so, 'Do any of your conditions or illnesses reduce your ability to carry out day-to-day activities? Please consider whether you are affected while receiving any treatment or medication for your condition or illness and/or using any devices such as a hearing aid, for example' (HSE 2012 onwards). Respondents were considered to have a limiting long-standing illness, and thus being unhealthy, if they responded yes to both questions (with activity restriction 'yes, a little' or 'yes, a lot' in 2012-2014). Respondents were otherwise considered healthy.

Work was defined as participation in paid employment or self-employment (or away temporarily) within the week preceding that of the interview.

Statistical methods. A three-state model was used to estimate and project HWLE for men and women in England: healthy and working (state 1); unhealthy and/ or not working (state 2); and dead (state 3) (Supplementary Fig. 1). HWLE was calculated and forecasted based on a progressive illness-death model where irreversible transitions can occur: from healthy and working to unhealthy and/or not working (transition from state 1 to state 2); from healthy and working to dead (state 1 to state 3); and from unhealthy and/or not working to dead (state 2 to state 3) (Supplementary Fig. 1). Since in reality individuals may exit and reenter the healthy working state, this approach assumes modeling net transition rates ${ }^{7,48}$.

The HWLE from 1996 to 2014 was estimated separately for men and women using the intercensal approach ${ }^{5,7}$. In this health expectancy estimation method, transition probabilities and transition rates are inferred from age-specific mortality rates for each calendar year, age-specific prevalence of being healthy and in work for each calendar year and the ratio of mortality rates $R$ from the unhealthy and/or not working state (state 2 ) compared to the healthy working state (state 1 ). $R$ was treated as a constant with the assumption that the relationship with mortality of health and work status was the same for all ages, calendar years and sexes ${ }^{48}$.

For each year of age from 50 to 75 in each calendar year 1996-2014, the population prevalence of being healthy and in work was taken as locally estimated scatterplot smoothed values of the HSE observed prevalence of being healthy and in work (separately for men and women). Smoothing of age-specific prevalence of being healthy and in work was improved by including values set to zero for ages 76-79.

$R$ could not be directly estimated because no suitable data source could be identified. Instead, $R$ was approximated as 1.04 by comparing hazard ratios for the two transitions to death associated with each additional year of age in a continuous time, 3-state model Markov chain analysis of data from the English Longitudinal Study of Ageing (Supplementary Note).

HWLE projections up to the year 2035 were estimated by combining the intercensal method (for estimating health expectancies) with the Lee-Carter forecasting approach (used to forecast the transition rates that are the basis of the intercensal method HWLE estimates $)^{8}$. HWLE was projected for the years 2015 to 2035 using Lee-Carter forecasts of transition rates for the permitted transitions in the 3-state model and Lee-Carter forecasts of age-specific mortality rates. (Observed mortality rate data were used for the 2015-2018 HWLE projections. $)^{5,7,47,49}$. In the Lee-Carter method, age-specific mortality rates are forecasted through singular value decomposition of the log of the age-specific mortality rates and subsequently modeling the time component as a random walk with $\mathrm{drift}^{8}$. Autoregressive integrated moving average (ARIMA) $(0,1,1)$ time series models were used to estimate the prevalence of being healthy and in work at age 50 in projected years for men and women ${ }^{48}$.

HWLE 95\% CIs were derived from the 95\% CIs of Lee-Carter vectors of change over time for both the overall mortality and transition rates from healthy and working to unhealthy and/or not working, as well as the 95\% CIs for ARIMA forecasted population prevalence of being healthy and in work at age 50 .

The upper and lower estimated bounds for projections of the transition rate from healthy and working to unhealthy and/or not working were implausible at ages 52, 53 and 54 for men; to avoid the CIs of HWLE encompassing negative values, upper and lower bounds for this transition rate were linearly interpolated using the bounds estimated at ages 51 and 55 . All analyses were performed in R v.3.6.2.

Sensitivity analyses. To assess the validity of the projection model and HWLE estimates, observed (1996-2014) and forecasted HWLE (2015-2017) were estimated separately using the Sullivan method ${ }^{50}$. The Sullivan method is an approach that has been widely used to estimate health expectancies using crosssectional data, with the assumption that the proportion of people alive or healthy at each age does not change over time, for simplicity or where longitudinal approaches were not feasible $\mathrm{e}^{5,50}$. (The most recent HSE years 2015-2017 could be used in this sensitivity analysis since grouped ages can be analyzed using the Sullivan method.)

The potential impact on HWLE estimates and projections of taking $R$ as 1.04 was examined using sensitivity analyses taking $R$ as 1 (mortality rates are assumed to be the same from healthy and working state 1 and unhealthy and/or not working state 2 ) and taking $R$ as 2 (mortality rates are assumed to be twice as high from unhealthy and/or not working state 2 compared to healthy and working state 1 ).

Reporting Summary. Further information on research design is available in the Nature Research Reporting Summary linked to this article.

\section{Data availability}

Data from the HSE is available without restriction to registered researchers from the UK Data Service (https://doi.org/10.5255/UKDA-SN-7919-3). HSE data collected in the years 1996-2018 were used in this study. Mortality rates were obtained from the 2018-based past and projected period and cohort life tables published by the UK ONS. All other data are available from the corresponding author upon reasonable request.

Received: 7 May 2021; Accepted: 6 December 2021; Published online: 20 January 2022

\section{References}

1. Department for Work and Pensions. State Pension Age Review: Final Report https://www.gov.uk/government/publications/state-pension-age-review-final report (2017).

2. Reeuwijk, K. G., van Klaveren, D., van Rijn, R. M., Burdorf, A. \& Robroek, S J. W. The influence of poor health on competing exit routes from paid employment among older workers in 11 European countries. Scand. J. Work Environ. Health 43, 24-33 (2017).

3. Parker, M., Bucknall, M., Jagger, C. \& Wilkie, R. Population-based estimates of healthy working life expectancy in England at age 50 years: analysis of data from the English Longitudinal Study of Ageing. Lancet Public Health $\mathbf{5}$, e395-e403 (2020).

4. Office for National Statistics. Single-Year Life Tables, UK: 1980 to 2020 https:// www.ons.gov.uk/peoplepopulationandcommunity/birthsdeathsandmarriages/ lifeexpectancies/datasets/singleyearlifetablesuk1980to2018 (2019).

5. Guillot, M. \& Yu, Y. Estimating health expectancies from two cross-sectional surveys: the intercensal method. Demogr. Res. 21, 503-534 (2009).

6. NatCen Social Research, University College London \& Department of Epidemiology and Public Health. Health Survey for England, 2014 (Data Collection) https://doi.org/10.5255/UKDA-SN-7919-3 (2018).

7. Majer, I. M., Stevens, R., Nusselder, W. J., Mackenbach, J. P. \& van Baal, P. H. M. Modeling and forecasting health expectancy: theoretical framework and application. Demography 50, 673-697 (2013).

8. Lee, R. D. \& Carter, L. R. Modeling and Forecasting U.S. Mortality. J. Am. Stat. Assoc. 87, 659-671 (1992).

9. United Nations. World Population Prospects 2019 https://population.un.org/ wpp/ (2019).

10. Wilkie, R., Blagojevic-Bucknall, M., Jordan, K. P. \& Pransky, G. Onset of work restriction in employed adults with lower limb joint pain: individual factors and area-level socioeconomic conditions. J. Occup. Rehabil. 23, 180-188 (2013). 
11. Muszyńska, M. M. \& Rau, R. The old-age healthy dependency ratio in Europe. J. Popul. Ageing 5, 151-162 (2012).

12. Haan, P. \& Myck, M. Dynamics of health and labor market risks. J. Health Econ. 28, 1116-1125 (2009).

13. Davies, N. M., Dickson, M., Davey Smith, G., va den Berg, G. J. \& Windmeijer, F. The causal effects of education on health outcomes in the UK Biobank. Nat. Hum. Behav. 2, 117-125. (2018).

14. Cantu, P. A., Sheehan, C. M., Sasson, I. \& Hayward, M. D. Increasing education-based disparities in healthy life expectancy among U.S. nonHispanic whites, 2000-2010. J. Gerontol. B Psychol. Sci. Soc. Sci. 76, 319-329 (2021).

15. Vlassoff, C. Gender differences in determinants and consequences of health and illness. J. Health Popul. Nutr. 25, 47-61 (2007).

16. Cooper, R. et al. Age and gender differences in physical capability levels from mid-life onwards: the harmonisation and meta-analysis of data from eight UK cohort studies. PLoS ONE 6, e27899 (2011).

17. Parker, M., Bucknall, M., Jagger, C. \& Wilkie, R. Extending working lives: a systematic review of healthy working life expectancy at age 50. Soc. Indic. Res. 150, 337-350 (2020).

18. Lièvre, A. et al. Healthy working life expectancies at age 50 in Europe: a new indicator. J. Nutr. Health Aging 11, 508-514 (2007).

19. Jagger, C. et al. The burden of diseases on disability-free life expectancy in later life. J. Gerontol. A Biol. Sci. Med. Sci. 62, 408-414 (2007).

20. Bennett, H. Q. et al. Healthy ageing for all? Comparisons of socioeconomic inequalities in health expectancies over two decades in the Cognitive Function and Ageing Studies I and II. Int. J. Epidemiol. 50, 841-851 (2021).

21. Welsh, C. E., Matthews, F. E. \& Jagger, C. Trends in life expectancy and healthy life years at birth and age 65 in the UK, 2008-2016, and other countries of the EU28: an observational cross-sectional study. Lancet Reg. Health Eur. 2, 100023 (2021).

22. Wilkie, R., Bjork, M., Costa-Black, K. M., Parker, M. \& Pransky, G. Managing work participation for people with rheumatic and musculoskeletal diseases. Best Pract. Res. Clin. Rheumatol. 4, 101517 (2020).

23. Van Aerden, K., Puig-Barrachina, V., Bosmans, K. \& Vanroelen, C. How does employment quality relate to health and job satisfaction in Europe? A typological approach. Soc. Sci. Med. 158, 132-140 (2016).

24. Burgard, S. A. \& Lin, K. Y. Bad jobs, bad health? How work and working conditions contribute to health disparities. Am. Behav. Sci. 57, https://doi. org/10.1177/00027642134873 (2013).

25. Siegrist, J., Wahrendorf, M., von dem Knesebeck, O., Jürges, H. \& BörschSupan, A. Quality of work, well-being, and intended early retirement of older employees: baseline results from the SHARE Study. Eur. J. Public Health 17, 62-68 (2007).

26. Johri, R. Work Values and the Quality of Employment: a Literature Review https://thehub.swa.govt.nz/assets/documents/Work\%20values\%20and\%20 the $\% 20$ quality $\% 20$ of\%20employment, $\% 20 \mathrm{a} \% 20$ literature\%20review.pdf (2005).

27. Loichinger, E. \& Weber, D. Trends in working life expectancy in Europe. J. Aging Health 28, 1194-1213 (2016).

28. Jagger, C. Trends in Life Expectancy and Healthy Life Expectancy. https:// assets.publishing.service.gov.uk/government/uploads/system/uploads/ attachment_data/file/464275/gs-15-13-future-ageing-trends-life-expectancyer12.pdf (2015).

29. Robroek, S. J. W., Schuring, M., Croezen, S., Stattin, M. \& Burdorf, A. Poor health, unhealthy behaviors, and unfavorable work characteristics influence pathways of exit from paid employment among older workers in Europe: a four year follow-up study. Scand. J. Work Environ. Health 39, 125-133 (2013)

30. Schuring, M., Robroek, S. J. W., Otten, F. W. J., Arts, C. H. \& Burdorf, A. The effect of ill health and socioeconomic status on labor force exit and re-employment: a prospective study with ten years follow-up in the Netherlands. Scand. J. Work Environ. Health 39, 134-143 (2013).

31. Wagenaar, A. F., Kompier, M. A. J., Houtman, I. L. D., van den Bossche, S. N. J. \& Taris, T. W. Employment contracts and health selection: unhealthy employees out and healthy employees in? J. Occup. Environ. Med. 54, 1192-1200 (2012).

32. Schuring, M., Burdorf, L., Kunst, A. \& Mackenbach, J. The effects of ill health on entering and maintaining paid employment: evidence in European countries. J. Epidemiol. Community Health 61, 597-604 (2007).

33. Public Health England. Chapter 1: Life Expectancy and Healthy Life Expectancy https://www.gov.uk/government/publications/health-profile-forengland/chapter-1-life-expectancy-and-healthy-life-expectancy (2017).

34. Public Health England. Health Profile for England: 2019. Chapter 1: Population, Deaths, Life Expectancy and Healthy Life Expectancy (Data Tables). https://www.gov.uk/government/publications/health-profile-for-england-2019 (2019).
35. Department for Work and Pensions. State Pension Age Timetable. https://www.gov.uk/government/publications/state-pension-age-timetable/ state-pension-age-timetable (2014).

36. Boissonneault, M. \& Rios, P. Changes in healthy and unhealthy working-life expectancy over the period 2002-17: a population-based study in people aged 51-65 years in 14 OECD countries. Lancet Healthy Longev. 2, e629-e638 (2021).

37. Dhillon, P. \& Ladusingh, L. Working life gain from gain in old age life expectancy in India. Demogr. Res. 28, 733-762 (2013).

38. Taylor, N. A job, any job: the UK benefits system and employment services in an age of austerity. Obs. Soc. Br. 19, 267-285 (2017).

39. Reeves, A., Basu, S., McKee, M., Marmot, M. \& Stuckler, D. Austere or not? UK coalition government budgets and health inequalities. J. R. Soc. Med. 106, 432-436 (2013).

40. Barr, B., Taylor-Robinson, D., Scott-Samuel, A., McKee, M. \& Stuckler, D. Suicides associated with the 2008-10 economic recession in England: time trend analysis. BMJ 345, e5142 (2012).

41. Office for National Statistics. Deaths Registered Weekly in England and Wales, Provisional https://www.ons.gov.uk/peoplepopulationandcommunity/ birthsdeathsandmarriages/deaths/datasets/ weeklyprovisionalfiguresondeathsregisteredinenglandandwales (2021).

42. Armitage, R. \& Nellums, L. B. Considering inequalities in the school closure response to COVID-19. Lancet Glob. Health 8, e644 (2020).

43. Buck, R. et al. Challenges to remaining at work with common health problems: what helps and what influence do organisational policies have? J. Occup. Rehabil. 21, 501-512 (2011).

44. Office for National Statistics. Past and Projected Period and Cohort Life Tables, 2018-based, UK: 1981 to 2068 https://www.ons.gov.uk/ peoplepopulationandcommunity/birthsdeathsandmarriages/lifeexpectancies/ bulletins/pastandprojecteddatafromtheperiodandcohortlifetables/1981 to2068 (2019).

45. Au, N. \& Johnston, D. W. Self-assessed health: what does it mean and what does it hide? Soc. Sci. Med 121, 21-28 (2014).

46. Kingston, A., Robinson, L., Booth, H., Knapp, M. \& Jagger, C. Projections of multi-morbidity in the older population in England to 2035: estimates from the Population Ageing and Care Simulation (PACSim) model. Age Ageing 47, 374-380 (2018)

47. NatCen Social Research. Health Survey for England, 2014 https://digital.nhs uk/data-and-information/publications/statistical/health-survey-for-england/ health-survey-for-england-2014 (2014).

48. Cao, B. Future healthy life expectancy among older adults in the US: a forecast based on cohort smoking and obesity history. Popul. Health Metr. 14, 23 (2016)

49. Lee, R. \& Miller, T. Evaluating the performance of the Lee-Carter method for forecasting mortality. Demography 38, 537-549 (2001).

50. Jagger, C., Van Oyen, H. \& Robine, J.-M. Health Expectancy Calculation by the Sullivan Method: a Practical Guide (Nihon Univ. Population Research Institute, 2014).

\section{Acknowledgements}

This work was supported by the Economic and Social Research Council (grant no. ES/P000665/1 to M.L.). The funders had no role in study design, data collection and analysis, decision to publish or preparation of the manuscript.

\section{Author contributions}

M.L., M.B., C.J. and R.W. designed the research. M.L. conducted the research, interpreted the findings and wrote the paper under the supervision of M.B., C.J. and R.W.

\section{Competing interests}

The authors declare no competing interests.

\section{Additional information}

Supplementary information The online version contains supplementary material available at https://doi.org/10.1038/s43587-021-00161-0.

Correspondence and requests for materials should be addressed to Marty Lynch.

Peer review information Nature Aging thanks Paola Zaninotto, Ewan MacDonald and the other, anonymous, reviewer(s) for their contribution to the peer review of this work.

Reprints and permissions information is available at www.nature.com/reprints.

Publisher's note Springer Nature remains neutral with regard to jurisdictional claims in published maps and institutional affiliations.

(c) The Author(s), under exclusive licence to Springer Nature America, Inc. 2022 


\section{Reporting Summary}

Nature Research wishes to improve the reproducibility of the work that we publish. This form provides structure for consistency and transparency in reporting. For further information on Nature Research policies, see our Editorial Policies and the Editorial Policy Checklist.

\section{Statistics}

For all statistical analyses, confirm that the following items are present in the figure legend, table legend, main text, or Methods section.

$\mathrm{n} / \mathrm{a}$ Confirmed

$\bigotimes$ The exact sample size $(n)$ for each experimental group/condition, given as a discrete number and unit of measurement

$\square$ \ A statement on whether measurements were taken from distinct samples or whether the same sample was measured repeatedly

Х The statistical test(s) used AND whether they are one- or two-sided

Xnly common tests should be described solely by name; describe more complex techniques in the Methods section.

Х $\square$ A description of all covariates tested

\A description of any assumptions or corrections, such as tests of normality and adjustment for multiple comparisons

A full description of the statistical parameters including central tendency (e.g. means) or other basic estimates (e.g. regression coefficient) AND variation (e.g. standard deviation) or associated estimates of uncertainty (e.g. confidence intervals)

For null hypothesis testing, the test statistic (e.g. $F, t, r$ ) with confidence intervals, effect sizes, degrees of freedom and $P$ value noted

$\triangle$ Give $P$ values as exact values whenever suitable.

Х $\square$ For Bayesian analysis, information on the choice of priors and Markov chain Monte Carlo settings

Х $\square$ For hierarchical and complex designs, identification of the appropriate level for tests and full reporting of outcomes

$\triangle \square$ Estimates of effect sizes (e.g. Cohen's $d$, Pearson's $r$ ), indicating how they were calculated

Our web collection on statistics for biologists contains articles on many of the points above.

\section{Software and code}

Policy information about availability of computer code

Data collection No software was used for data collection

Data analysis All analyses were performed in R software (version 3.6.2)

For manuscripts utilizing custom algorithms or software that are central to the research but not yet described in published literature, software must be made available to editors and

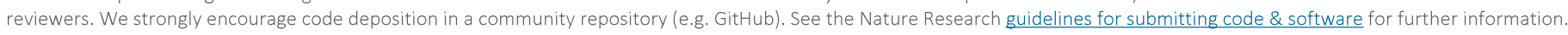

Data

Policy information about availability of data

All manuscripts must include a data availability statement. This statement should provide the following information, where applicable:

- Accession codes, unique identifiers, or web links for publicly available datasets

- A list of figures that have associated raw data

- A description of any restrictions on data availability

HSE data for years 1996-2018 were obtained from the UK Data Service (freely available to researchers from http://doi.org/10.5255/UKDA-SN-7919-3). Mortality rates were obtained from the UK Office for National Statistics 2018-based past and projected period and cohort life tables. 
Please select the one below that is the best fit for your research. If you are not sure, read the appropriate sections before making your selection.

$\square$ Life sciences $\quad \bigotimes$ Behavioural \& social sciences $\quad \square$ Ecological, evolutionary \& environmental sciences

For a reference copy of the document with all sections, see nature.com/documents/nr-reporting-summary-flat.pdf

\section{Behavioural \& social sciences study design}

All studies must disclose on these points even when the disclosure is negative.

Study description

Research sample

Sampling strategy

Data collection

Timing

Data exclusions

Non-participation

Randomization

\section{Quantitative population study using repeated cross-sectional survey data}

We analysed nationally representative cross-sectional survey data collected from 1996-2014 (with 2015-18 data used in sensitivity analyses) in the Health Survey for England (HSE) - available from http://doi.org/10.5255/UKDA-SN-7919-3. We used health and work data collected from adults aged 50 years and over. This dataset was selected as it contains the relevant health and work data for our study and the repeated design allowed use of existing health expectancy and projection methods.

For each HSE year, households were selected randomly to be invited to participate. In each selected household, all individuals were eligible for inclusion in the survey. HSE surveys 1996-2014 were used in the main analysis as 1996 was the first year with the health and work questions and 2014 was the final year for which data were released with individual (not grouped) year of age. Data up to 2018 (the most recent data at time of analysis) were used in sensitivity analyses.

Computer Assisted Personal Interviewing software was used for personal interviews with participants. This study is a secondary analysis of the HSE data and as such interviewers were not aware of the research focus.

For each of the 13 yearly HSE surveys (1996-2018) used in this study, interviews were carried out throughout the entire calendar year.

Due to low rates of missingness, participants with missing health or work data ( $\mathrm{n}<=10$ at each HSE year) were excluded from the study sample. For the main analysis (1996-2014), the number excluded due to missingness was: 1996 (0), 1997 (3), 1998 (8), 1999

(3), 2000 (7), 2001 (9), 2002 (3), 2003 (9), 2004 (6), 2005 (8), 2006 (5), 2007 (3), 2008 (9), 2009 (2), 2010 (2), 2011 (3), 2012 (9), 2013 (3), 2014 (10).

This study was a secondary data analysis of data collected in the yearly national Health Survey for England (HSE). HSE household response rates from 1996 to 2014 ranged from 62\%-79\%. For data collected from 2003 onwards, HSE weights (introduced in 2003) were used to reduce non-response bias. Household response rates: 1996 (79\%), 1997 (76\%), 1998 (74\%), 1999 (76\%), 2000 (75\%), 2001 (74\%), 2002 (74\%), 2003 (73\%), 2004 (72\%), 2005 (74\%), 2006 (68\%), 2007 (64\%), 2008 (64\%), 2009 (68\%), 2010 (66\%), 2011 (66\%), 2012 (64\%), 2013 (64\%), 2014 (62\%).

The study was observational

\section{Reporting for specific materials, systems and methods}

We require information from authors about some types of materials, experimental systems and methods used in many studies. Here, indicate whether each material, system or method listed is relevant to your study. If you are not sure if a list item applies to your research, read the appropriate section before selecting a response.

\begin{tabular}{|c|c|}
\hline$n / a$ & Involved in the study \\
\hline Х & $\square$ Antibodies \\
\hline Х & Eukaryotic cell lines \\
\hline$\bigotimes$ & $\square$ Palaeontology and archaeology \\
\hline Х & $\square$ Animals and other organisms \\
\hline Х & $\square$ Human research participants \\
\hline Х & $\square$ Clinical data \\
\hline Х & $\square$ Dual use research of concern \\
\hline
\end{tabular}

Methods
\begin{tabular}{l|l}
$\mathrm{n} / \mathrm{a}$ & Involved in the study \\
$\square$ & $\square$ ChIP-seq \\
$\square$ & $\square$ Flow cytometry \\
$\square$ & $\square$ MRI-based neuroimaging
\end{tabular}

